\title{
Improving Energy Efficiency of Existing Residential Buildings Using Effective Thermal Retrofit of Building Envelope
}

\author{
Claire Far ${ }^{1}$, Harry Far ${ }^{2 *}$ \\ 1-Faculty of Design, Architecture and Building, University of Technology Sydney (UTS), Australia \\ 2-Centre for Built Infrastructure Research (CBIR), Faculty of Engineering and Information Technology, \\ University of Technology Sydney (UTS), Australia
}

\begin{abstract}
Upgrading the energy efficiency of existing buildings is a well-known issue around the globe. Given the very low renewal rate of the building stock, thermal retrofit of the existing buildings seems to be a good solution to improve the environmental performance of the building sector. Several studies have acknowledged the lack of knowledge, experience and best-practice examples as barriers in thermal retrofit of existing buildings. Therefore, this study has focused on developing recommendations on the most effective and feasible retrofitting techniques for existing buildings and performing financial analysis of initial investment vs return based on the quantitative results of the energy modelling. Thermal comfort modelling software FirstRate5 has been used to simulate the annual heating and cooling energy consumption of nine benchmark buildings through a range of retrofitting techniques. Dwellings of varying construction materials including weatherboard, cavity brick and brick veneer have been simulated to improve accuracy. Examining seven different thermal retrofitting options in this study, it has become apparent that there is significant heating and cooling energy reduction, with payback period of less than three years, by implementing two options of the examined retrofitting cases to existing residential dwellings.
\end{abstract}

Keywords: Energy Efficiency, Existing Buildings, Thermal Retrofit, Thermal Comfort, Environmental Performance, Payback Period

\section{Introduction}

Upgrading the energy efficiency of existing buildings is a well-known issue. As elucidated by Poel et al. (2007) ${ }^{1}$ given the very low renewal rate of the building stock, refurbishment of the existing buildings can be a good solution to improve the environmental performance of the building sector. According to Power $(2008)^{2}$ the existing stock exceeds the number of newly built buildings. While new constructions add annually $1 \%$ or less to the existing stock, the other $99 \%$ of buildings are already built and produce about $24 \%$ of the energy-use induced carbon emissions. Regarding materials and waste, studies show that the environmental impact of life cycle extension of a building is definitely less than demolition and new construction. ${ }^{3}$ The retrofitting of

\footnotetext{
* Corresponding author: Lecturer in Engineering, Centre for Built Infrastructure Research, Faculty of Engineering and Information Technology, University of Technology Sydney (UTS), Building 11, Level 11, Broadway, Ultimo NSW
} 
existing buildings in particular provides considerable potential for energy conservation and further sustainable benefits. Recent figures suggest the domestic sector could potentially make a significant contribution to reducing energy consumption. ${ }^{4}$ Residential buildings account for $70 \%$ of building floor area ${ }^{4}$ while the condition and efficiency of a large part of the residential stock still needs attention. About $2 / 3$ of the existing buildings are over 30 years old and about $40 \%$ are over 50 years old. ${ }^{1,3}$ This is an important observation given that most national building regulations that mandate thermal insulation of building envelopes were introduced following the energy crisis in the 1970s. ${ }^{3}$ Furthermore, buildings suffer from a variety of physical problems. Taking into account that the expectation for the structural life of a building often exceeds 60 years, while the envelope shows signs of obsolescence after only 20 or 30 years ${ }^{5}$, it is understandable that the residential stock is in need of refurbishment. The current energy and climate change impacts of the residential building sector in Australia are significant. Thus, the Australian Government has introduced more stringent regulations to improve building energy efficiency ${ }^{6}$. In 2006, the Australian residential building sector consumed about $11 \%$ (around 440 Petajoule) of the total primary energy, resulting in total greenhouse gas emissions of 9.65 million tonnes CO2-eq. ${ }^{7}$ According to Department of the Environment, Water, Heritage and the Arts (2008) report $^{8}$, the gas and electricity consumption of residential dwellings contributed to $30 \%$ and $52 \%$ respectively, of the total primary energy utilised by this sector. The report highlights that around $40 \%$ of total energy consumption of Australian buildings goes to heating and cooling due to the low thermal performance of the buildings.

Thermal performance of buildings determines the amount of energy used for heating and cooling of the buildings which profoundly influences energy efficiency. Therefore, employing sustainable design principles and effective use of construction materials can play a crucial role in improving thermal performance of new and existing buildings. ${ }^{9}$ Even though awareness has been raised, the design phase of refurbishment projects is often problematic. One of the issues concerning the refurbishment of residential buildings is mostly the consumer market ${ }^{3}$, where most work consists of moderate refurbishment jobs, often without assistance of an architect and partly without a 
building permit. There is an individual and often fragmental approach that results in lack of efficiency. ${ }^{10}$ Most importantly, the decisions are taken in the early stages of the design determine the final result. However, the assessment of the environmental performance only happens at the end of the design process, as a reflection of the design outcome. ${ }^{10}$

Many researchers (e.g. Zinzi and Fasano $2009^{11}$; Synnefa et al. $2012^{12}$; Karabay and Arıc1 $2012^{13}$; Pisello $2017^{14}$; Mansoury and Tabatabaiefar $2016{ }^{15}$; Hernández-Pérez et al. $2018^{16}$ ) have acknowledged the lack of knowledge, experience and best-practice examples as barriers in refurbishment projects. In the context of sustainable development and the need to reduce energy demand, refurbishing the ageing residential buildings constitutes a necessary action. Not only does it provide huge potential for energy savings, but also it is economically and socially relevant. ${ }^{10,17}$ Although the advantages have been identified, the guidelines come in the form of general suggestions that fail to address the diversity of each project. ${ }^{17}$ Therefore, it has become apparent that there is a strong need to develop tools for optimised retrofitting of existing residential buildings in order to improve their energy performance. As a result, this study focuses on developing recommendations on the most effective and feasible retrofitting techniques for existing building located in Sydney (Australia) and performing financial analysis of initial investment vs return based on the quantitative results of the energy modelling. Thermal comfort modelling software FirstRate5 has been used to simulate the annual heating and cooling energy consumption of nine case study buildings through a range of retrofitting techniques. Dwellings of varying construction materials including weatherboard, cavity brick and brick veneer have been simulated to improve accuracy. Each case study building will be subjected to seven retrofitting cases to produce a consistent set of results. Examining different retrofitting cases for the case study buildings, this study aims to identify the two most effective retrofitting techniques with significant heating and cooling energy reduction which are worthwhile investments and will provide financial return. 


\section{Theoretical Background of Building Envelop Thermal Retrofit}

According to Australian Building Codes Board $(2016)^{18}$, the building envelop is the physical boundary which separates the habitable areas from the external environment. The building envelope consists of external walls, external doors, windows, roof, ground and the internal walls that separate conditioned spaces from non-condition spaces as illustrated in Figure 1.

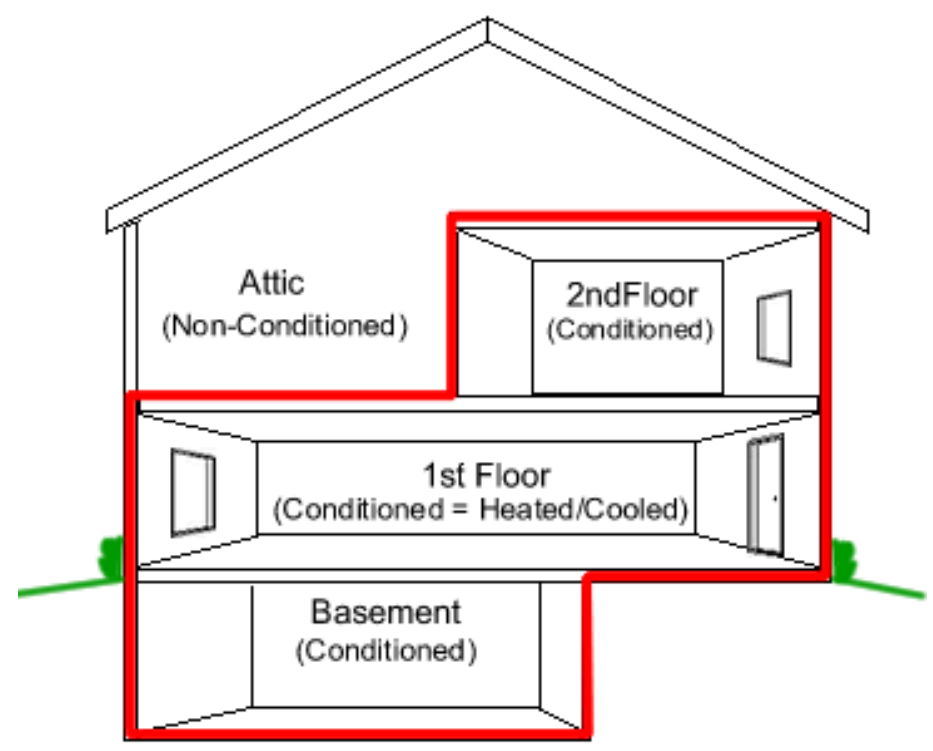

Figure1: Building Envelop Diagram ${ }^{18}$

Thermal insulation is the reduction of heat transfer between objects in thermal contact or in range of radiative influence. ${ }^{19}$ Thermal insulation can be achieved with especially engineered methods or processes, as well as with suitable object shapes and materials. Heat flow is an inevitable consequence of contact between objects of differing temperature. Thermal insulation provides a region of insulation in which thermal conduction is reduced or thermal radiation is reflected rather than absorbed by the lower-temperature body. As defined by Bergman et al. (2011) ${ }^{19}$, in a building, the thermal performance of insulation is expressed by $R$-value (thermal resistance) which is measured in watt-per-meter-per-kelvin $\left(\mathrm{W} \cdot \mathrm{m}^{-1} \cdot \mathrm{K}^{-1}\right.$ ), while the thermal performance of glazing is expressed by $U$ - value (thermal conduction) as shown by Equation 1 below:

$U=\frac{1}{R}$ 
Therefore, $U$-value is the inverse of $R$-value.

According to Bergman et al. $(2011)^{19}$, Fourier's law states that the conduction of heat is directly proportional to the difference in temperature of each side of a surface. As a result, doubling the temperature difference inherently doubles the flow of heat. The heat transfer rate $Q$ (loss or gain) can be determined by combining the thermal performance with Fourier's law as shown by Equation 2 below:

$$
Q=\frac{A}{R} \cdot \Delta T
$$

where, $R$ is the thermal resistance, $A$ is the area of the surface $\left(\mathrm{m}^{2}\right)$, and $\Delta T$ is the difference in temperature between both sides of the surface $\left({ }^{\circ} \mathrm{C}\right)$.

National Construction Code $(2016)^{20}$ states that the total $R$-value of a building element will not only take into account any additional insulation, but also other construction materials such as plasterboards, air cavities, brick/timber and air films. Since thermal resistances in series can be added, the total $R$-value is the sum of all materials. ${ }^{21}$ Therefore, an uninsulated external wall such as brick veneer will have an $R$-value of around 0.5 and with the addition of 2.5 bulk insulation; the total thermal resistance will be 3.0 .

Thermal mass is the ability of a material to absorb and store heat energy. Thermal mass effects occur in buildings containing walls, floors and ceilings made of materials such as masonry (brick) and concrete. ${ }^{21}$ Materials such as timber and metal cladding provide little thermal mass. ${ }^{22}$ A material specific heat capacity determines its thermal mass capability. Specific heat capacity is defined as the amount of heat that a kilogram of a given substance is required to absorb in order to increase its temperature by one degree. ${ }^{19}$ Therefore, the higher the specific heat capacity, the more heat energy is required to change the temperature of that material. This also means that the material will lose that heat at a slower rate. ${ }^{21}$ Reilly and Kinnane $(2017)^{22}$ stated that the thermal mass of a material $\left(C_{t h}\right)$ can be determined by Equation 3 as follows:

$$
C_{t h}=m \cdot C_{p}
$$

where, $m$ is the mass of the body and $C_{p}$ is the specific heat capacity. 
The ability to absorb large amounts of heat energy and then to release the heat at a slow rate gives high thermal mass materials (material with higher $C_{t h}$ values) the advantage of having better thermal performance. During winter, the material will absorb heat energy throughout the day and then releases the heat throughout the night when temperatures begin to fall. ${ }^{21}$ This substantially contributes in keeping the house at a more consistent temperature. Conversely, during summer, the high thermal mass of the dwelling will drop in temperature throughout the night and slowly heat throughout the day, again maintaining a more consistent temperature. ${ }^{22}$ Correct use of thermal mass in the form of thermal insulation can delay the heat flow through the building envelope by as much as 10-12 hours, producing a warmer house at night in winter and a cooler house during the day in summer. ${ }^{21}$ Thermal insulation in the building envelop is an extremely effective way of reducing heat transfer between conditioned and non-conditioned areas and improving the thermal comfort of a dwelling. As a result, national building regulations mandating thermal insulation of building envelopes were introduced in the 1970s, in response to the energy crisis. ${ }^{3}$ Thermal insulation provides an addition $\mathrm{R}$-value to the building envelope. This will increase the thermal resistance and subsequently reduces heat transfer. Figure 2 illustrates the percentage of heat transfer that occurs in an uninsulated dwelling, depending on hot or cold external weather. If the external temperature is lower compared to the internal temperature, heat will be transferred out to the external environment. Alternatively, if the external temperature is higher in comparison to the internal temperature, heat will be transferred into the internal environment. $^{23}$
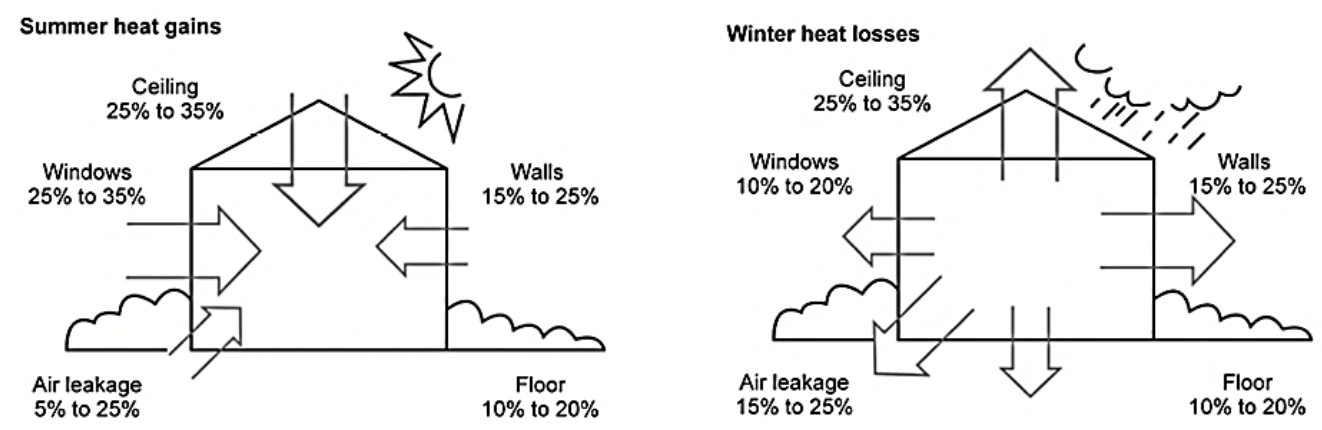

Figure 2: Heat flow in an uninsulated dwelling ${ }^{23}$ 


\section{Characteristics of Case Study Buildings}

This study has adopted a case study research method approach. This approach provides practical and real world mean to investigate the amount of heating and cooling operational energy in the existing buildings and provide opportunities to identify improvements to energy efficiency. Therefore, a number of case study buildings located in Sydney metropolitan area (Australia) which are older than 20 years have been selected. The case study buildings consist of various construction materials and have been chosen as the benchmark for modelling and simulation purposes. All plans have been sourced from their relevant council websites for development applications on exhibition. The three construction materials for case study buildings are Weatherboard (timber cladding), Brick Veneer (single brick) and Cavity Brick (double brick with cavity). Three dwellings of each construction material have been selected for a total of nine case study buildings. Having a sample size of three dwellings of each construction material has increased the accuracy of the project outcomes. Table 1 tabulates a summary of the relative information for each case study building.

Table 1: Relative information of employed case study buildings

\begin{tabular}{cllcl}
\hline No. & Suburb & Wall Material & Year built & \multicolumn{1}{c}{ Address } \\
\hline 1 & Berowra & Weatherboard & 1978 & Yallambee Rd, Berowra NSW 2081 \\
2 & Dulwich Hill & Cavity Brick & 1900 & Jesmond Ave, Dulwich Hill NSW 2203 \\
3 & Dural & Brick Veneer & 1999 & Caber Cl, Dural NSW 2158 \\
4 & Enmore & Cavity Brick & 1910 & Browns Ave, Enmore NSW 2042 \\
5 & Hornsby & Weatherboard & 1965 & Binnari Rd, Hornsby Heights NSW 2077 \\
6 & Pennant Hills & Weatherboard & 1960 & Malahide Rd, Pennant Hills NSW 2120 \\
7 & North Epping & Cavity Brick & 1900 & Norfolk Rd, North Epping NSW 2121 \\
8 & Castle Hill & Brick Veneer & Pre 1990 & Highclere Pl, Castle Hill NSW 2154 \\
9 & Thornleigh & Brick Veneer & Pre 1990 & Morgan St, Thornleigh NSW 2120 \\
\hline
\end{tabular}

\section{Computer Modelling and Analysis}

FirstRate 5 software has been utilised in this study to model and estimate the annual heating and cooling energy usage of the case study buildings by taking into account 
factors such as climate zone, conditioned area, zone occupation hours, glazing area, construction materials, orientation and shading. This software is an interactive tool with a graphic user interface that enables designers and thermal performance assessors to generate energy ratings for a home by tracing over floor plan. Compared to other thermal comfort modelling software, FirstRate5 is more comprehensive and suited to modelling detached buildings such as houses. ${ }^{15}$ A preliminary validation of the numerical models has been carried out in FirstRate 5 by simulating the building model created by Manosury and Tabatabaiefar (2016). ${ }^{15}$ Comparing the numerical results, it was revealed that FirstRate5 numerical models used in this study can replicate the results reported by Manosury and Tabatabaiefar $(2016)^{15}$ with acceptable accuracy.

As the first step of modelling, floor plans for case study buildings have been drawn in AutoCAD. Then, FirstRate 5 models have been generated by importing scaled AutoCAD floor plans into the user interface (Figure 3). Therefore, geometric details of the floor plans can be read and interpreted precisely by the software. Each room within the floor plans is then traced over to produce a $2 \mathrm{D}$ model. In the next step, windows, doors and other internal and external openings are added to the model.

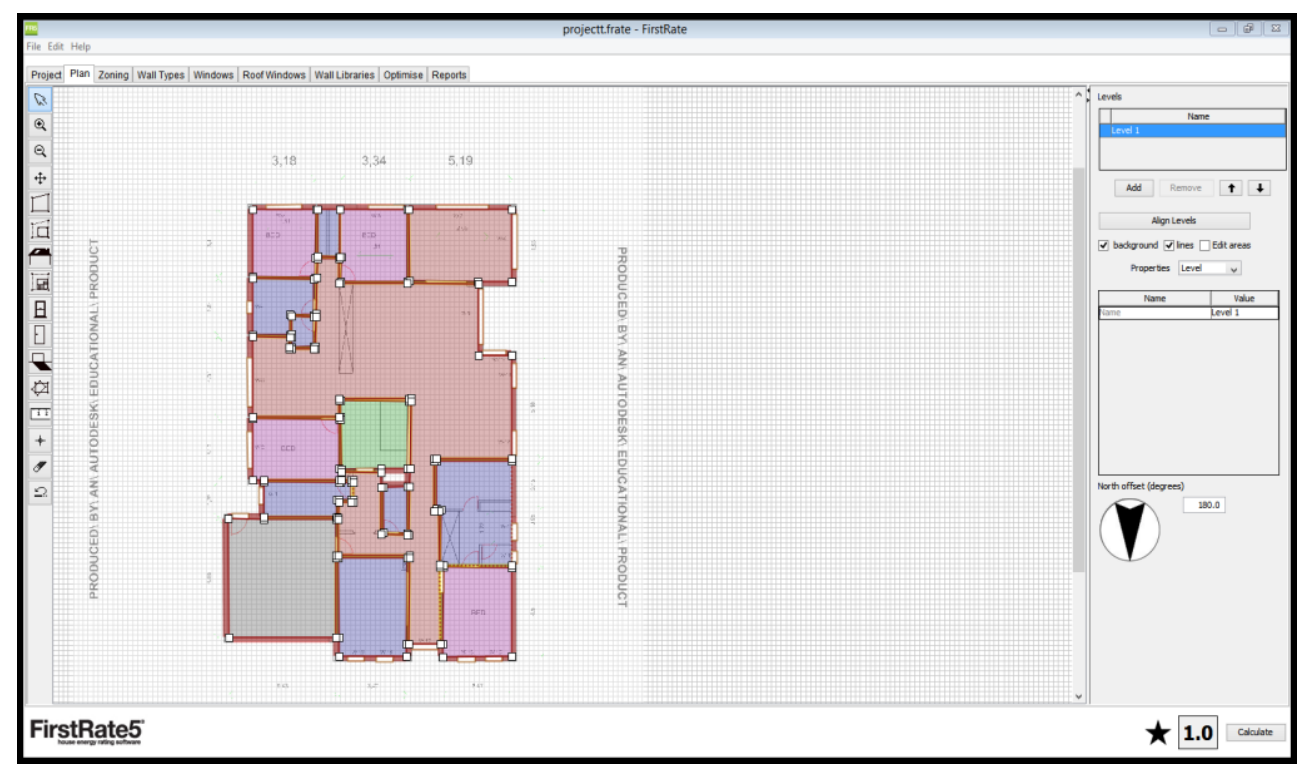

Figure 3: Floor and zoning plan in FirstRate5 user interface 
Climate data, orientation and any shadings is then added. Afterwards, five different zone classifications have been introduced to the program and assigned to each zone of each building considering type of occupancy, internal heat generation and ventilation as summarised in Table 2. Each occupancy zone is shown with different colour in Figure 3. In the end, the construction details of dwellings have been added into each model for accurate simulation of energy usage. Externals walls, internal walls, floor, and roof materials were all entered, respectively.

Table 2: Different zone classifications

\begin{tabular}{ll}
\hline \multicolumn{1}{c}{ Type of Zone } & \multicolumn{1}{c}{ Details of occupancy } \\
\hline Living & Conditioned from 7-24. Daytime occupancy. No cooking heat gain. \\
Bedroom & Conditioned from 16-9. Night-time occupancy. \\
Kitchen & Conditioned from 7-24. Daytime occupancy. Cooking heat included. \\
Other(daytime usage) & If heat and/or cooled, conditioned from7-24. No occupancy heat gain. \\
Other(night-time usage) & If heated and/or cooled, conditioned from 16-9. No occupancy gains. \\
Garage & No conditioned in this research \\
\hline
\end{tabular}

To have further consistency between the models, identical wall construction details have been selected for all weatherboard, cavity brick and brick veneer materials, respectively. Using the 'Wall Builder' function within FirstRate5, three wall types have been created to accurately model common weatherboard, brick cavity and brick veneer walls. The insulation added to each wall type is 'Rockwool Loose Fill'. According to FirstRate5 wall builder, Rockwool loose fill insulation has a specificity conductivity of $0.04 \mathrm{~W} / \mathrm{m} . \mathrm{k}$. Therefore, according to Equation 1, to obtain the R-values, the inverse of conductivity has been multiplied by the thickness of insulations and the R-values were applied to each building model, respectively.

\section{Employed Building Envelop Thermal Retrofit Techniques}

There are a number of studies that have evaluated existing residential buildings in Australia and proposed retrofitting techniques to improve energy efficiency of the studied buildings. Iyer-Raniga and Wong $(2012)^{24}$ have studied 8 benchmark buildings across Victoria with different construction materials. They simulated the case study buildings in AccuRate software and proposed some building interventions to improve energy efficiency of the case study buildings. They concluded that adding insulation to the 
ceiling in the model was the most effective and provided the highest energy saving and reduced life cycle primary energy and carbon emissions significantly. Manosury and Tabatabaiefar $(2016)^{15}$ studied a case study building in Melbourne to serve as the benchmark building for modelling and simulation purposes. Based on the research findings, it has become apparent that the most effective and feasible method of retrofitting the case study building is adding insulation layers to the ceiling level. Since adding insulation layers to the celling has been recognised to be the most efficient thermal retrofit technique in Australia so far, in this study, the first thermal retrofitting stage considers celling thermal retrofit. Using FirstRate5, each dwelling has been subjected to the same seven retrofitting cases to produce a consistent set of results. These seven cases can be broken up into three following stages;

> Stage 1 - Gradual increase in ceiling insulation from R2.0-R6.0

> Stage 2 - R3.0 ceiling insulation, in combination with Rockwool loose fill external wall insulation of $\mathrm{R} 1.25$ for $50 \mathrm{~mm}$ cavity and $\mathrm{R} 2.25$ for $90 \mathrm{~mm}$ airspace

$>$ Stage 3 - Stage 2, in combination with R1.0 suspended floor insulation for dwellings with timber suspended floors

It should be noted that due to the ages of the dwellings and deterioration of insulation over time, reference models have been modelled with no insulation. This also gives each model a standardised started point for retrofitting. Table 3 summarises the retrofitting techniques and insulation R-values for all seven cases.

Table 3: Employed thermal retrofitting technique R-values

\begin{tabular}{cccc}
\hline Case & $\begin{array}{c}\text { Wall insulation } \\
\text { (R-value) }\end{array}$ & $\begin{array}{c}\text { Ceiling Insulation } \\
\text { (R-value) }\end{array}$ & $\begin{array}{c}\text { Floor Insulation } \\
\text { (R-value) }\end{array}$ \\
\hline $\mathbf{0}$ (Reference) & Nil & Nil & Nil \\
$\mathbf{1}$ & Nil & 2 & Nil \\
$\mathbf{2}$ & Nil & 3 & Nil \\
$\mathbf{3}$ & Nil & 4 & Nil \\
$\mathbf{4}$ & Nil & 5 & Nil \\
$\mathbf{5}$ & Nil & 6 & Nil \\
$\mathbf{6}$ & $1.25 / 2.25$ & 3 & Nil \\
$\mathbf{7}$ & $1.25 / 2.25$ & 3 & 1 \\
\hline
\end{tabular}




\section{Results and Discussion}

The FirstRate5 software has simulated the annual heating and cooling energy consumption for all dwellings and cases of retrofitting. Results of computer modelling and analysis are summarised and graphed in Figures 4-6 for visual representation of the change in heating, cooling and total energy usage for each dwelling and case. Tabulated results in Tables 4-6 are taken directly from the results produced by FirstRate5 after each simulation. The annual heating and cooling energy is shown in the units of mega Jules per metre squared. Combining the annual heating and cooling energy gives the total energy. Reduction from reference is the percentage decrease in the total energy usage for that case compared to the reference case. The obtained results have been interpreted, analysed and compared in order to identify the most effective and efficient retrofitting technique to improve the energy efficiency of the benchmark buildings.

\section{Weatherboard Dwellings}

Table 4 and Figure 4 illustrate the average results for the three weatherboard dwellings. The addition of R2-6 ceiling insulation within the weatherboard dwellings produces a significant decrease in total heating and cooling energy of 47\%-52\% from the reference.

Table 4: Weatherboard material average results

\begin{tabular}{|c|c|c|c|c|c|}
\hline \multicolumn{6}{|c|}{ Stage 1 - Ceiling Insulation } \\
\hline Case & R-value & $\begin{array}{l}\text { Heating } \\
\left(\mathrm{MJ} / \mathrm{m}^{2}\right)\end{array}$ & $\begin{array}{l}\text { Cooling } \\
\left(\mathrm{MJ} / \mathrm{m}^{2}\right)\end{array}$ & $\begin{array}{c}\text { Total } \\
\left(\mathbf{M J} / \mathbf{m}^{2}\right)\end{array}$ & $\begin{array}{c}\text { Reduction From } \\
\text { Reference }\end{array}$ \\
\hline $\mathbf{0}$ & 0 & 215.7 & 94.4 & 310.0 & \\
\hline 1 & 2 & 120.3 & 45.5 & 165.8 & $47 \%$ \\
\hline 2 & 3 & 115.0 & 43.6 & 158.6 & $49 \%$ \\
\hline 3 & 4 & 112.1 & 42.4 & 154.6 & $50 \%$ \\
\hline 4 & 5 & 110.3 & 41.8 & 152.1 & $51 \%$ \\
\hline 5 & 6 & 109.0 & 41.2 & 150.2 & $52 \%$ \\
\hline \multicolumn{6}{|c|}{ Stage 2 - Case $2+$ Wall Insulation } \\
\hline 6 & 2.25 & 66.3 & 30.0 & 96.3 & $69 \%$ \\
\hline \multicolumn{6}{|c|}{ Stage 3 - Case $6+$ Suspended Floor Insulation } \\
\hline 7 & 2.25 & 54.6 & 36.3 & 90.8 & $71 \%$ \\
\hline
\end{tabular}


Stage 2 of retrofitting produces a decrease of $69 \%$ by installing R2.25 of Rockwool insulation into the external walls. This is a substantial decrease of $213 \mathrm{MJ} / \mathrm{m} 2$ from the reference. Further retrofitting to Stage 3 by installing R1 floor insulation to dwellings with suspended timber floors produces a decrease of $71 \%$ from reference. However, this is only a reduction of $6 \%$ compared to Stage 2 . The small improvement is due to the summer cooling load increasing when floor insulation is applied. This is expected due to underfloor ventilation loses.

\section{Weatherboard Dwellings Results}

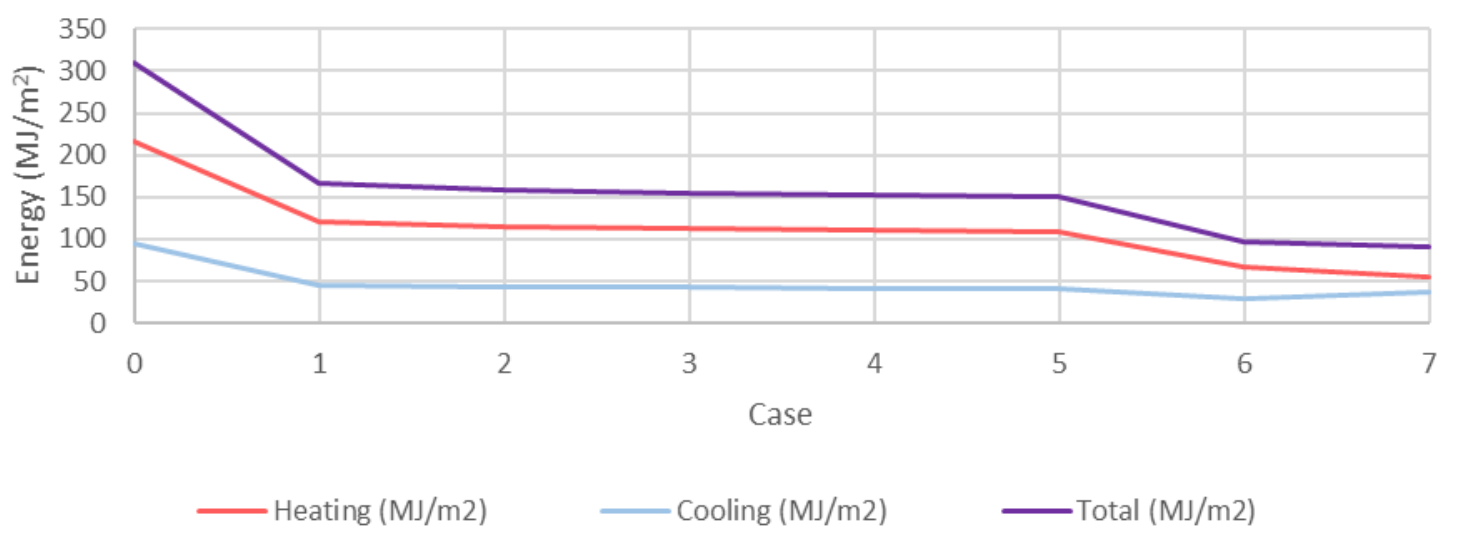

Figure 4: Weatherboard material average results

\section{Cavity Brick Dwellings}

Table 5 and Figure 5 demonstrate the average results for the three cavity brick dwellings. The addition of R2-6 ceiling insulation within the cavity brick dwellings produces a significant decrease in total heating and cooling energy of $62 \%-66 \%$ from the reference. Stage 2 of retrofitting produces a decrease of $77 \%$ by installing R1.25 of Rockwool insulation into the external walls. This is a substantial decrease of $228.8 \mathrm{MJ} / \mathrm{m}^{2}$ from the reference. Further retrofitting to Stage 3 by installing R1 floor insulation to dwellings with suspended timber floors produces a decrease of $83 \%$ from reference. This is a reduction of $28 \%$ compared to Stage 2. However, as only one of the cavity brick dwellings (Dulwich Hill) had a suspended floor, the Stage 3 results of only Dulwich Hill is being compared to the three dwelling average Stage 2 results. This is producing an exaggerated reduction of $28 \%$. 
Table 5: Cavity Brick material average results

\begin{tabular}{cccccc}
\hline Case & R-value & $\begin{array}{c}\text { Heating } \\
\left(\mathbf{M J} / \mathbf{m}^{2}\right)\end{array}$ & $\begin{array}{c}\text { Cooling } \\
\left(\mathbf{M J} / \mathbf{m}^{2}\right)\end{array}$ & $\begin{array}{c}\text { Total } \\
\left(\mathbf{M J} / \mathbf{m}^{2}\right)\end{array}$ & $\begin{array}{c}\text { Reduction From } \\
\text { Reference }\end{array}$ \\
\hline $\mathbf{0}$ & 0 & 208.7 & 89.9 & 298.7 & $62 \%$ \\
$\mathbf{1}$ & 2 & 87.9 & 25.5 & 113.4 & $64 \%$ \\
$\mathbf{2}$ & 3 & 82.6 & 24.2 & 106.8 & $65 \%$ \\
$\mathbf{3}$ & 4 & 80.5 & 23.6 & 104.1 & $66 \%$ \\
$\mathbf{4}$ & 5 & 78.7 & 23.3 & 102.1 & $66 \%$ \\
$\mathbf{5}$ & 6 & 77.5 & 23.1 & 100.6 & $77 \%$ \\
\hline $\mathbf{6}$ & 1.25 & 49.8 & 20.1 & 69.9 & $83 \%$ \\
\hline $\mathbf{7}$ & 1.25 & \multicolumn{7}{c}{ Case 6 + Suspended Floor Insulation } \\
\hline
\end{tabular}

\section{Cavity Brick Dwellings Results}

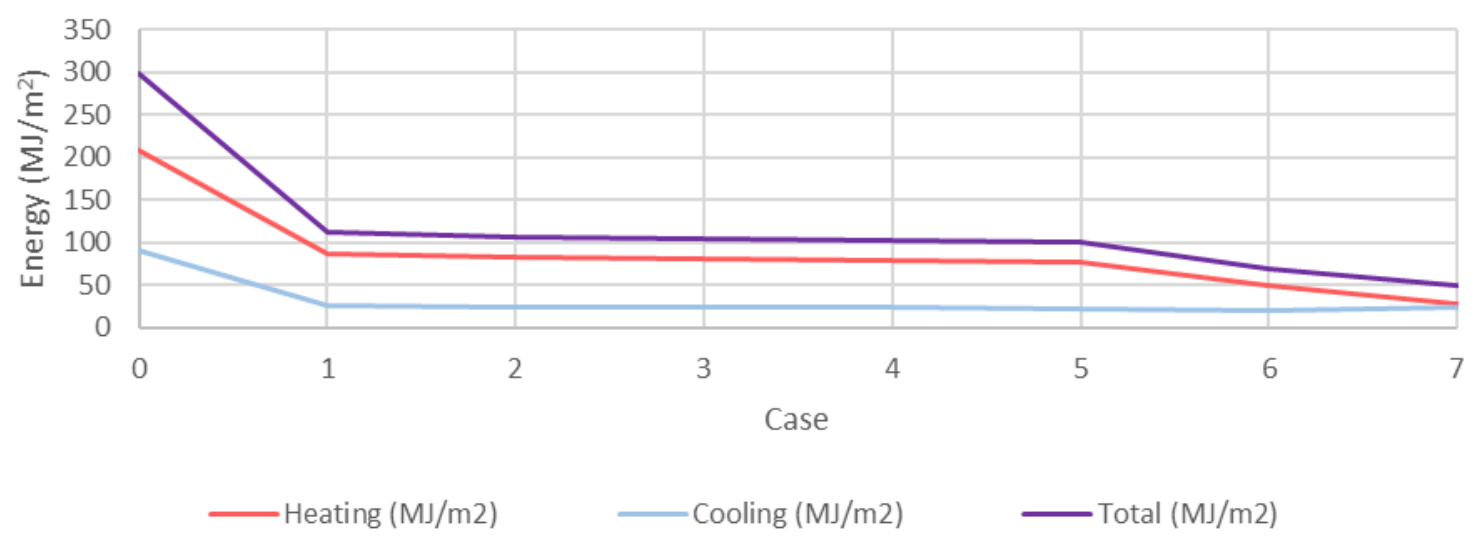

Figure 5: Cavity Brick material average results

\section{Brick Veneer Dwellings}

Table 6 and Figure 6 indicate the average results for the three brick veneer dwellings. The addition of R2-6 ceiling insulation within the brick veneer dwellings produces a significant decrease in total heating and cooling energy of 44\%-49\% from the reference. Stage 2 of retrofitting produces a decrease of $69 \%$ by installing R1.25 of Rockwool insulation into the external walls. This is a substantial decrease of $197.1 \mathrm{MJ} / \mathrm{m}^{2}$ from the reference. As all brick 
veneer benchmark dwellings were concrete slab on ground construction, Stage 3 could not be tested for brick veneer dwellings.

Table 6: Brick Veneer material average results

\begin{tabular}{|c|c|c|c|c|c|}
\hline \multicolumn{6}{|c|}{ Ceiling Insulation } \\
\hline Case & R-value & $\begin{array}{l}\text { Heating } \\
\left(\mathbf{M J} / \mathbf{m}^{2}\right)\end{array}$ & $\begin{array}{l}\text { Cooling } \\
\left(\mathbf{M J} / \mathbf{m}^{2}\right)\end{array}$ & $\begin{array}{c}\text { Total } \\
\left(\mathbf{M J} / \mathbf{m}^{2}\right)\end{array}$ & $\begin{array}{c}\text { Reduction From } \\
\text { Reference }\end{array}$ \\
\hline $\mathbf{0}$ & 0 & 202.9 & 84.0 & 286.9 & \\
\hline 1 & 2 & 112.9 & 46.7 & 159.6 & $44 \%$ \\
\hline 2 & 3 & 108.1 & 45.1 & 153.2 & $47 \%$ \\
\hline 3 & 4 & 105.6 & 44.5 & 150.1 & $48 \%$ \\
\hline 4 & 5 & 103.9 & 43.9 & 147.8 & $48 \%$ \\
\hline 5 & 6 & 102.8 & 43.5 & 146.4 & $49 \%$ \\
\hline \multicolumn{6}{|c|}{ Case $2+$ Wall Insulation } \\
\hline 6 & 2.25 & 57.3 & 32.5 & 89.8 & $69 \%$ \\
\hline \multicolumn{6}{|c|}{ Case 6 + Suspended Floor Insulation } \\
\hline 7 & 0 & & All C & ab On Gro & \\
\hline
\end{tabular}

\section{Brick Veneer Dwellings Results}

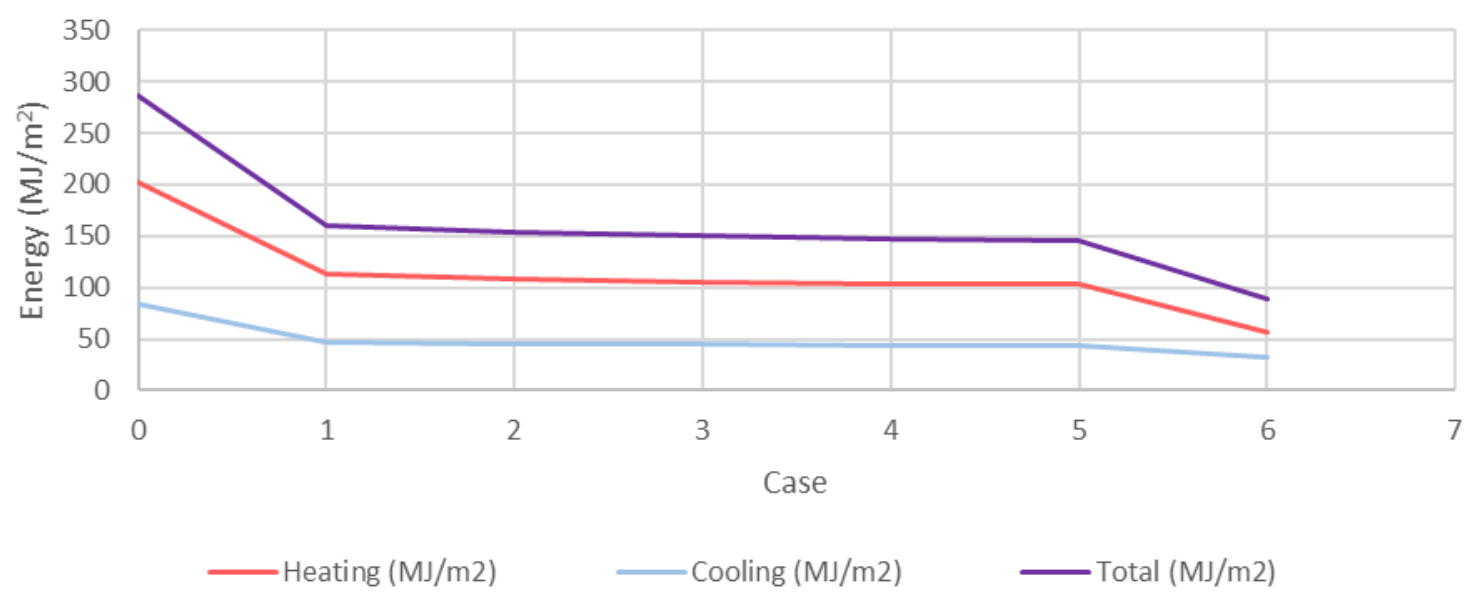

Figure 6: Brick Veneer material average results

\section{Discussion and Comparison}

It can be seen from Table 7 and Figure 7 that weatherboard, cavity brick and brick veneer dwellings follow the same trends during retrofitting cases. Case 1 from reference provides 
the largest improvement, while Case 1 to Case 5 provide only a small diminishing improvement. Case 5 to Case 6 produces another step improvement for all constructions when wall insulation is added. Case 6 to 7 produces a small further improvement for underfloor insulation.

Table 7: Construction material comparison

\begin{tabular}{|c|c|c|c|c|}
\hline \multicolumn{5}{|c|}{ Total Annual Heating and Cooling Energy $\left(\mathbf{M J} / \mathbf{m}^{2}\right)$} \\
\hline \multicolumn{5}{|c|}{ Ceiling Insulation } \\
\hline Case & R-value & Weatherboard & Cavity Brick & Brick Veneer \\
\hline $\mathbf{0}$ & 0 & 310.0 & 298.7 & 286.9 \\
\hline 1 & 2 & 165.8 & 113.4 & 159.6 \\
\hline 2 & 3 & 158.6 & 106.8 & 153.2 \\
\hline 3 & 4 & 154.6 & 104.1 & 150.1 \\
\hline 4 & 5 & 152.1 & 102.1 & 147.8 \\
\hline 5 & 6 & 150.2 & 100.6 & 146.4 \\
\hline \multicolumn{5}{|c|}{ Case $2+$ Wall Insulation } \\
\hline 6 & $1.25 / 2.25$ & 96.3 & 69.9 & 89.8 \\
\hline \multicolumn{5}{|c|}{ Case 6 + Suspended Floor Insulation } \\
\hline 7 & 1 & 90.8 & 50.5 & \\
\hline
\end{tabular}

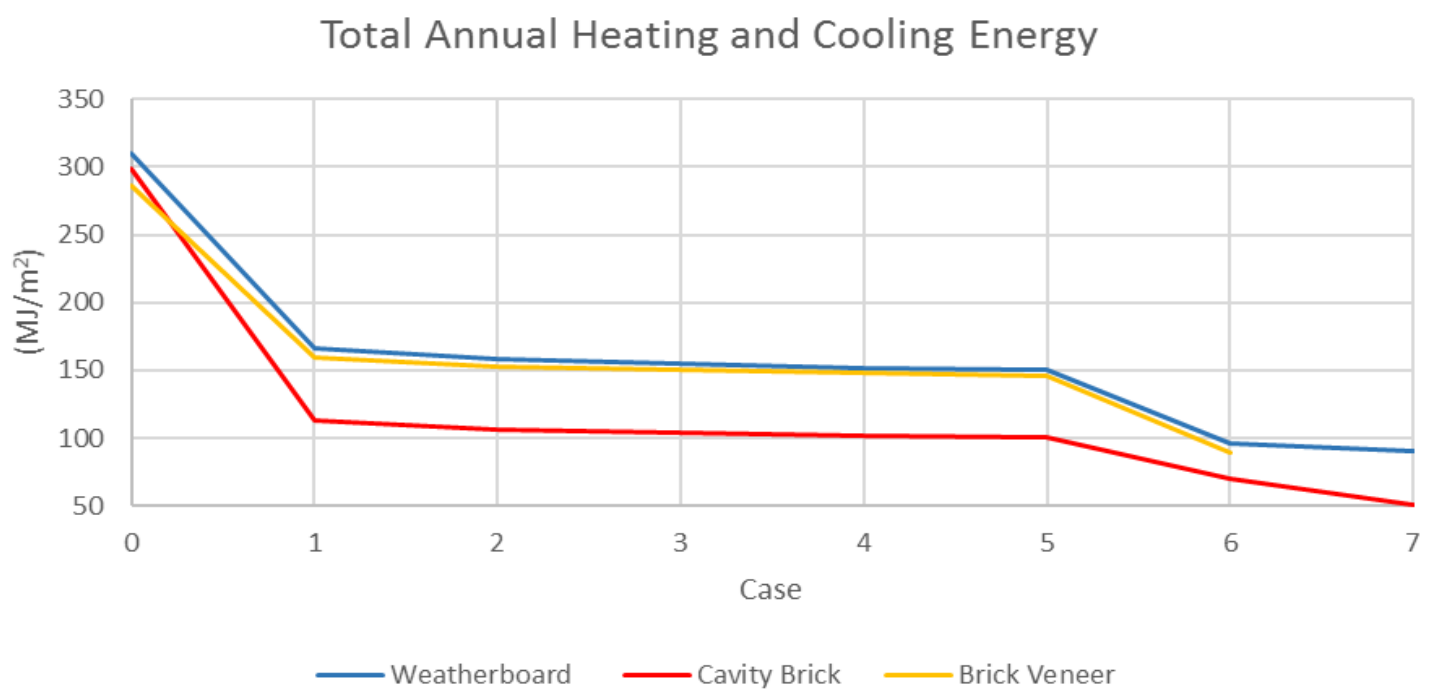

Figure 7: Construction material comparison 
As the three construction types follow the same trends when subjected to the retrofitting cases, it can be understood that the type of wall construction has a significant impact the dwellings improvement in heating and cooling energy usage. All construction materials follow the same progression and improve to a similar degree with the addition of insulation. Therefore, the results for all construction types can be combined and analysed together to draw a generalised solution to retrofitting existing dwellings.

Though the dwellings follow the same trends, there are some key points to note. Figure 7 displays that weatherboard and brick veneer dwellings have performed relatively similar from Case 0 to 7 . Both construction types have begun within $7 \%$ of one another and have been as close as 3\%. Thus, it can be understood that weatherboard and brick veneer dwellings perform similar thermally, with no major differences between the dwellings. The brick veneer dwellings perform slightly better than the weatherboard dwellings. This is to be expected due to the slight thermal mass benefits of the single brick leaf compared to the timber cladding in the weatherboard dwellings.

The results also show that the cavity brick dwellings have benefited significantly more by retrofitting ceiling insulation than the weatherboard and brick veneer dwellings. In Case 0, reference, all construction materials are within $7 \%$ of each other. This difference jumps to over $32 \%$ for Case 2 , as the cavity brick dwellings improvement substantially better than the others. This is also expected due to the considerable extra thermal mass of the two brick leafs, which stores the heat energy, in combination with the insulation to prevent heat transfer. It can be seen that this is an ideal scenario for great thermal performance of dwellings, thermal mass in combination with correct insulation.

Table 8 and Figure 8 illustrate the total annual heating and cooling energy reduction from reference for each construction type compared to the combined. As results for each construction type follow the same progression as the combined, it can be further determined that a generalised retrofitting solution can be implemented into a dwelling of any construction material. 
Table 8: Percentage reduction comparison

\begin{tabular}{cccccc}
\hline \multicolumn{5}{c}{ Total Annual Heating and Cooling Energy Reduction from Reference } \\
\hline \multicolumn{5}{c}{ Ceiling Insulation } \\
\hline Case & R-value & Weatherboard & Cavity Brick & Brick Veneer & Combined \\
\hline $\mathbf{1}$ & 2 & $47 \%$ & $62 \%$ & $44 \%$ & $51 \%$ \\
$\mathbf{2}$ & 3 & $49 \%$ & $64 \%$ & $47 \%$ & $53 \%$ \\
$\mathbf{3}$ & 4 & $50 \%$ & $65 \%$ & $48 \%$ & $54 \%$ \\
$\mathbf{4}$ & 5 & $51 \%$ & $66 \%$ & $48 \%$ & $55 \%$ \\
$\mathbf{5}$ & 6 & $52 \%$ & $66 \%$ & $49 \%$ & $56 \%$ \\
\hline \multicolumn{7}{c}{ Case 2 + Wall Insulation } \\
\hline $\mathbf{6}$ & $1.25 / 2.25$ & $69 \%$ & $77 \%$ & $71 \%$ \\
\hline $\mathbf{7}$ & 1 & Case 6 + Suspended Floor Insulation \\
\hline
\end{tabular}

TOTAL ANNUAL HEATING AND COOLING REDUCTION FROM REFERENCE

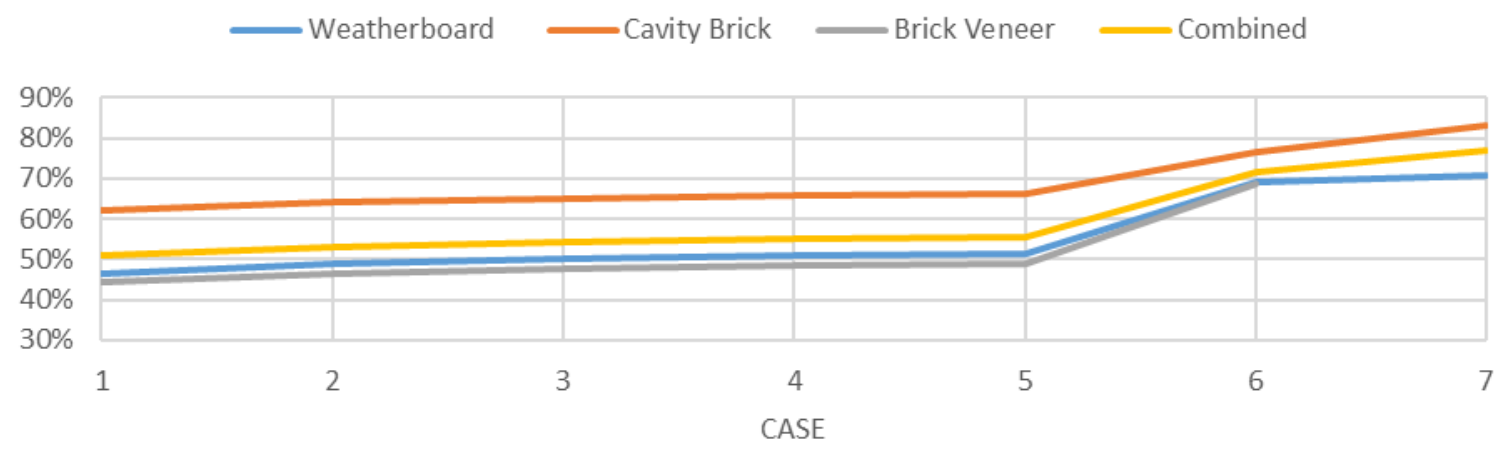

Figure 8: Percentage reduction comparison

\section{Combined Retrofitting Solution and Recommendations}

Table 9 tabulates the average results for the all benchmark dwellings graphed in Figure 9. The addition of R2-6 ceiling insulation within the benchmark dwellings produces a significant decrease in total heating and cooling energy of 51\%-56\% from the reference.

The simulation has shown that any additional ceiling insulation over R2 will roughly half the amount of heating and cooling energy usage of the dwellings. This is an outstandingly positive result as installing ceiling level insulation is an easily achievable and non- 
destructive retrofitting technique that yields an excellent reduction in energy usage. There is a $5 \%$ reduction to $\mathrm{R} 3$ over $\mathrm{R} 2$ ceiling insulation.

Table 9: Average of all results

\begin{tabular}{cccccc}
\hline \multicolumn{5}{c}{ Ceiling Insulation } \\
\hline Case & R-value & $\begin{array}{c}\text { Heating } \\
\left(\mathbf{M J} / \mathbf{m}^{2}\right)\end{array}$ & $\begin{array}{c}\text { Cooling } \\
\left(\mathbf{M J} / \mathbf{m}^{2}\right)\end{array}$ & $\begin{array}{c}\text { Total } \\
\left(\mathbf{M J} / \mathbf{m}^{2}\right)\end{array}$ & $\begin{array}{c}\text { Reduction From } \\
\text { Reference }\end{array}$ \\
\hline $\mathbf{0}$ & 0 & 209.1 & 89.4 & 298.5 & \\
$\mathbf{1}$ & 2 & 107.0 & 39.2 & 146.2 & $51 \%$ \\
$\mathbf{2}$ & 3 & 101.9 & 37.6 & 139.5 & $53 \%$ \\
$\mathbf{3}$ & 4 & 99.4 & 36.8 & 136.3 & $54 \%$ \\
$\mathbf{4}$ & 5 & 97.7 & 36.3 & 134.0 & $55 \%$ \\
$\mathbf{5}$ & 6 & 96.5 & 36.0 & 132.4 & $56 \%$ \\
& \multicolumn{5}{c}{ Case 2 + Wall Insulation } \\
\hline $\mathbf{6}$ & $1.25 / 2.25$ & 57.8 & 27.5 \\
\hline 7
\end{tabular}

The advantages of higher ceiling insulation levels are not seen and there are diminishing returns once ceiling insulation is above R3. This is expected due to Sydney's mild to warm climate where keeping heating inside the dwelling is not essential. The thickness of a R3 ceiling batt can be between 130-160 mm depending on the material chosen. Commonly used glass wool, 'Pink Batts', are around 155mm thick. Based off supply and fit prices in Australia, R3 and R6 insulation cost $\$ 6.75$ and $\$ 16.00$ per square metre, respectively. This equates to a saving of $\$ 1388$ for a dwelling of $150 \mathrm{~m}^{2}$. For these reasons, R3 is the recommended retrofitting technique for ceiling insulation in Sydney dwellings. R3 produces an average of $159 \mathrm{MJ} / \mathrm{m}^{2}$ decrease in heating and cooling energy from the reference, equating to a $53 \%$ reduction. This significant decrease in energy usage, along with the price advantage over thicker insulation (R6), makes R3 ceiling insulation an effective and viable solution to retrofitting of existing Sydney residential dwellings.

Stage 2 of retrofitting produces a vast energy usage decrease of $71 \%$ to the reference by installing Rockwool loose fill insulation into the external walls, in combination with the R3 
ceiling insulation. R1.25 is installed into the $50 \mathrm{~mm}$ cavity and R2.25 into the $90 \mathrm{~mm}$ airspace. The results show that Stage 2 produces an average of $54.4 \mathrm{MJ} / \mathrm{m}^{2}$ reduction over R3 ceiling insulation alone. This equates to a further $39 \%$ reduction in heating and cooling energy usage. This further decrease of $39 \%$ is expected as detached houses have a large external wall to floor ratio, meaning that there is a large amount of external walls for heat to transfer through. As shown in the previous Section of this paper, increasing the thermal resistance (R-value) significantly reduces the heat transfer rate through a wall.

\section{All Dwellings Combined Results}

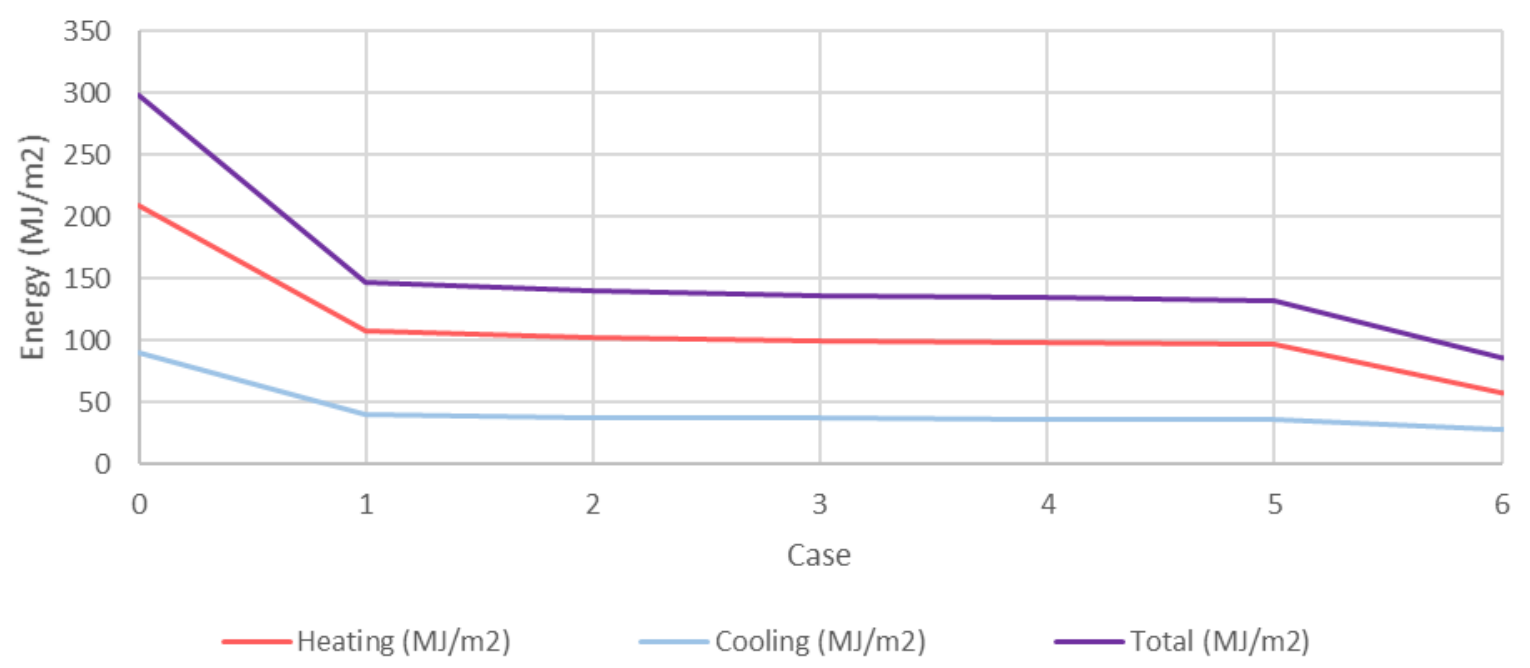

Figure 9: Average of all results

Installing Rockwool loose fill insulation into an external wall requires a more destructive method of retrofitting compared to ceiling insulation. Removing cladding / plasterboard, drilling / blocking holes or lifting roofing requires significant extra labour charges. Sustainability Victoria $(2016)^{25}$ installed loose fill Rockwool installation into a total of 15 dwellings at an average cost of $\$ 4,286$. This is significantly more expensive than $\mathrm{R} 3$ ceiling insulation due to the labour and equipment costs. Although Stage 2 requires a significantly larger initial investment to retrofit, the further $39 \%$ decrease in energy usage will mean that over a longer-term, Stage 2 will be more beneficial. For these reasons Stage 2 will be a second option of retrofitting if the homeowner would like to increase their initial investment. 
Stage 3 of the retrofitting involves installing under floor installation to the dwellings that contain suspended timber floors. This was in combination with Stage 2. There were limitations to Stage 3 as only 3 of the 9 benchmark dwellings contained suspended timber floors. As previously stated, this has exaggerated reduction when all averages are compared. For a more accurate result for Stage 3, Table 10 displays the average results for only the dwellings with suspended timber floors. It can now be seen that installing of an R1 insulation to the suspended floor yields a reduction in heating and cooling energy usage of 9\% compared to Stage 2 .

Table 10: Average results of suspended dwellings

\begin{tabular}{|c|c|c|c|c|c|}
\hline \multicolumn{6}{|c|}{ Ceiling Insulation } \\
\hline Case & R-value & $\begin{array}{l}\text { Heating } \\
\left(\mathrm{MJ} / \mathrm{m}^{2}\right)\end{array}$ & $\begin{array}{l}\text { Cooling } \\
\left(\mathbf{M J} / \mathbf{m}^{2}\right)\end{array}$ & $\begin{array}{c}\text { Total } \\
\left(\mathbf{M J} / \mathbf{m}^{2}\right)\end{array}$ & $\begin{array}{c}\text { Reduction From } \\
\text { Reference }\end{array}$ \\
\hline $\mathbf{0}$ & 0 & 202.6 & 86.2 & 288.8 & \\
\hline 1 & 2 & 100.7 & 39.2 & 139.9 & $52 \%$ \\
\hline 2 & 3 & 95.2 & 37.4 & 132.6 & $54 \%$ \\
\hline 3 & 4 & 92.2 & 36.1 & 128.3 & $56 \%$ \\
\hline 4 & 5 & 90.3 & 35.6 & 125.9 & $56 \%$ \\
\hline 5 & 6 & 88.9 & 35.1 & 124.0 & $57 \%$ \\
\hline \multicolumn{6}{|c|}{ Case 2 + Wall Insulation } \\
\hline 6 & $1.25 / 2.25$ & 57.3 & 27.1 & 84.4 & $71 \%$ \\
\hline \multicolumn{6}{|c|}{ Case 6 + Suspended Floor Insulation } \\
\hline 7 & 1 & 45.4 & 31.9 & 77.4 & $73 \%$ \\
\hline
\end{tabular}

Though spray foam insulation is a non-destructive method of retrofit, based off prices from current market in Australia, under floor spray foam insulation can cost up to $\$ 35$ per metre squared. Due to the high cost of retrofit compared to the energy saved, Stage 3 will not be further analysis or recommended as the results show that it is not a viable option.

\section{Feasibility Analysis}

Thermal comfort is the condition of mind that expresses satisfaction with the thermal environment and is assessed by subjective evaluation. ${ }^{26}$ Although thermal comfort is 
usually discussed for the body as a whole, thermal dissatisfaction may also occur just for a particular part of the body, due to local sources of unwanted heating, cooling or air movement. The prospect of thermal comfortability within your home should be important for all homeowners. Due to poor building envelop design constant use of mechanical heating and cooling appliances seem acceptable during summer and winter. Improvement of the building envelop would allow a dwelling to maintain a more consistent and acceptable temperature without the need for occupants to use such devices. The argument of investing money into retrofitting of an existing dwelling purely for occupants to feel more comfortable within their home would not be acceptable for the majority of homeowners. Considering that for many homeowners, the decision to retrofitting their dwelling will be made on whether it will be economical to do so, presenting a financial case and argument is necessary.

Demonstrating that the money invested into retrofitting techniques will provide a return on that investment, within a reasonable time, is vital to the success of implementation of the retrofitting techniques. The money saved from the reduction of energy bills will be considered as a financial gain. Therefore, in this study, two retrofitting technique options will be financially analysed based on the homeowner's initial investment amount.

- Option 1 - Case 2: R3 ceiling insulation.

- Option 2 - Case 6: R3 ceiling + external wall insulation

Each option will be investigated to determine the prices of retrofitting, money saved, payback period and return on investment. The following calculation are based off the assumption that all mechanical heating and cooling devices are powered off.

\section{Annual Heating and Cooling Electricity Cost}

Table 11 shows the average conditioned and unconditioned floor areas for all dwellings. These floor areas will be used for calculating the annual electricity demand for each case, as well as the amount of roof area that will require ceiling insulation. Table 12 summarises the cost of electricity based on AGL New South Wales Electricity Residential Single Rate Fact Sheet (2017). ${ }^{27}$ Theses electricity rates will be used to determine the annual cost of heating and cooling the average floor area. 
Table 11: average conditioned and unconditioned floor areas for all dwellings

\begin{tabular}{cc}
\hline Area & Size $\left(\mathbf{m}^{2}\right)$ \\
\hline Net Conditioned Floor Area (CFA) & 122.3 \\
\hline Unconditioned Floor Area & 10.5 \\
\hline Total Floor Area & 132.8 \\
\hline
\end{tabular}

Only the net conditioned floor area will be considered during calculations, as unconditioned areas are wet areas with openable windows or doors. As the outputs are presented in Mega Jules, a conversion rate of 3.6 is applied to convert to Kilo Watt Hours.

Table 12: Current AGL electricity rates ${ }^{24}$

\begin{tabular}{cc}
\hline \multicolumn{2}{c}{ AGL Electricity Rates } \\
\hline Usage Rate (\$/kWh) & 0.319 (inc' GST) \\
Daily Supply Charge (\$) & 0.924 (inc' GST) \\
\hline
\end{tabular}

Table 13 tabulates the annual electricity cost for all cases. It can be seen that the annual electricity cost decreases from Case 0 to Case 6. This is expected as the amount of heating and cooling energy demand decreases through each case. Option 1 and 2 produce an annual cost saving of $\$ 1,722.95$ and $\$ 2,310.27$, respectively.

Table 13: Average annual electricity cost for all case study dwellings

\begin{tabular}{ccc}
\hline Case & $\begin{array}{c}\text { Annual Electricity } \\
\text { Cost }\end{array}$ & $\begin{array}{c}\text { Savings from Reference Per } \\
\text { Year }\end{array}$ \\
\hline $\mathbf{0}$ & $\$ 3,571.85$ & \\
$\mathbf{1}$ & $\$ 1,921.51$ & $\$ 1,650.35$ \\
$\mathbf{2}-$ Option 1 & $\$ 1,848.90$ & $\$ 1,722.95$ \\
$\mathbf{3}$ & $\$ 1,814.23$ & $\$ 1,757.62$ \\
$\mathbf{4}$ & $\$ 1,789.30$ & $\$ 1,782.55$ \\
$\mathbf{5}$ & $\$ 1,771.97$ & $\$ 1,799.89$ \\
$\mathbf{6}-$ Option 2 & $\$ 1,261.58$ & $\$ 2,310.27$ \\
$\mathbf{7}$ & $\$ 1,175.98$ & $\$ 2,395.87$ \\
\hline
\end{tabular}




\section{Cost of Retrofitting Techniques}

The cost of each retrofitting technique option has been calculated based on a combination of online quotes and past research studies. Supply and fit quotes of $\$ 6.75$ per metre square for R3 insulation have been used for Option 1. A cost increase of 50\% has been applied as a safety factor to account for varying quotes and unforeseen extra costs. The total floor area has been considered for the following calculation, as the ceiling of unconditioned room will also be insulated to improve the effectiveness:

Option 1 R3 Ceiling Insulation $=(\$ 6.75 * 1.5) *$ Total Floor Area $=\$ 1,344.60$

Rockwool loose fill external wall insulation cost has been based off Sustainability Victoria $(2016)^{25}$. An average cost of $\$ 4286$ was recorded to install the pump in insulation into a total of 15 dwellings. A cost increase of $50 \%$ has also been applied as a safety factor to account for varying quotes and unforeseen extra costs.

Option 2 R3 Ceiling + External Wall Insulation $=\$ 1,344+(\$ 4286 * 1.5)=$ $\$ 7773.60$

Figure 10 illustrates the cost of each retrofitting techniques compared to the annual electricity savings per year.

Option 1 and 2 Comparison

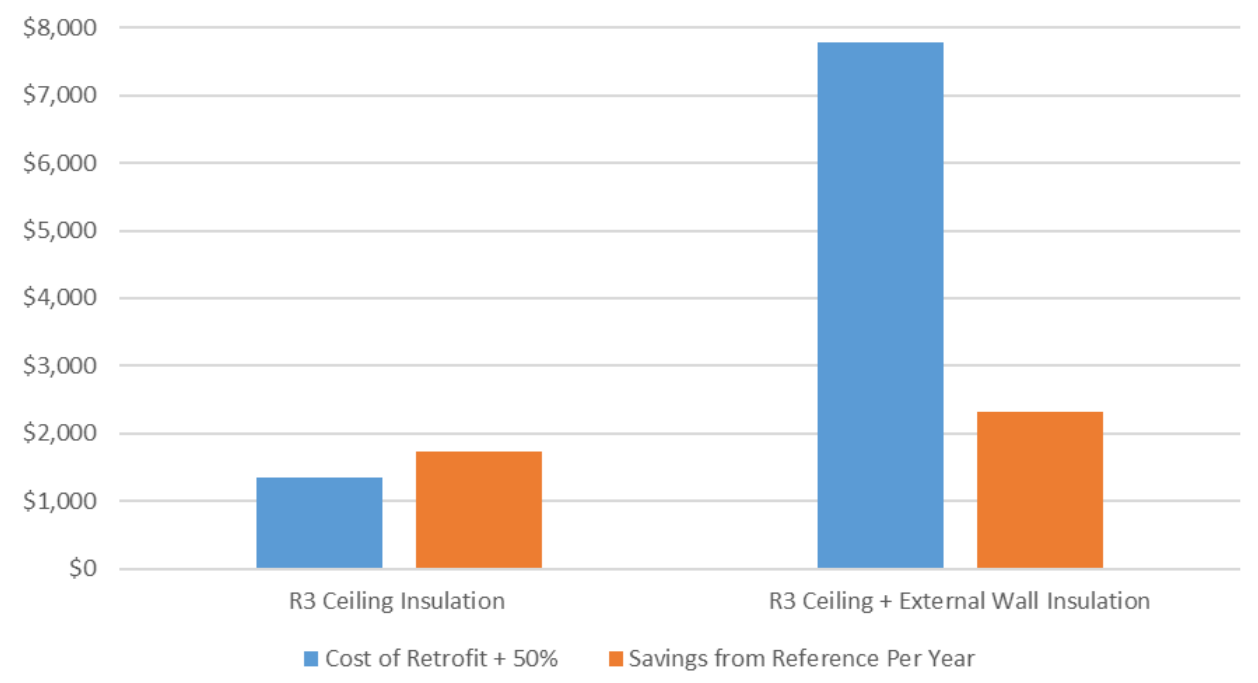

Figure 10: Cost of retrofit compared to annual savings per year 
It can be seen that for Option 1, the cost of retrofitting R3 ceiling insulation is less than the amount of money that will be saved per year. However, for Option 2, the price of retrofitting is significantly higher than the amount of money saved per year. This is an important factor to take into account when considering implementing Option 1 or Option 2.

\section{Pay Back Period and Return on Investment}

Table 14 shows the payback period, return on investment over 20 years and the annualised return on investment. These performance measurements are critical to accurately evaluate the financial benefits of retrofitting an existing dwelling. The payback period refers to the period time required to recuperate the costs put forward into an investment, or to reach the break-even point. Simply, this is the time taken for savings from electricity costs to cover the cost of retrofitting. This measurement will be the most important to most homeowners, as they would prefer to be 'out of pocket' for the least amount of time. Option 1 provides a payback period of 10 months.

Table 14: Cost of retrofit compared to annual savings per year

\begin{tabular}{ccc}
\cline { 2 - 3 } & Option 1- R3 Ceiling Insulation & $\begin{array}{c}\text { Option 2 - R3 Ceiling + } \\
\text { External Wall Insulation }\end{array}$ \\
\hline Cost of Retrofit & $\$ 1,344.60$ & $\$ 7,773.60$ \\
Savings from Reference Per Year & $\$ 1,722.95$ & $\$ 2,310.27$ \\
Payback Period (Months) & 10 & 41 \\
20 Year Return on Investment & $2464 \%$ & $494 \%$ \\
Return over 20 Years, minus initial cost & $\$ 33,114.40$ & $\$ 38,431.80$ \\
\hline
\end{tabular}

This is an exceptionally short payback period where the initial cost of investment will be paid back within the first year. Thus, making Option 1 an extremely viable and efficient means to retrofitting an existing building.

Option 2 provides a payback period of 41 months. This payback period is considerable longer than Option 1. This is to be expected as the price of retrofit is around 6 times higher while the savings improvements equate to around $34 \%$. However, a payback period of less than 3.5 years is relatively short considering the amount of money that will be continuingly 
saved after this payback period, so making Option 2 an extremely viable and efficient means to retrofitting an existing building.

Return on investment (ROI) is used to measure the efficiency of an investment and to compare different investments. ROI is a measure of the financial gain generated, over a period of time, by an investment relative to the amount of money initially invested as a percentage. Option 1 provides a ROI of $2464 \%$ over a 20 -year period, while Option 2 provides a ROI of $494 \%$ over the same period as displayed in Table 14.

Due to the lower initial cost of Option 1, the ROI is significantly higher than option 2. However, because of this lower initial cost, the ROI does not accurately display the benefits of the money saved by Option 2 over this 20-year period. Money saved over the 20 years, minus the initial investment will more accurately compare the two options over this 20-year period. It can be seen that over the 20 -year period, there will be an extra $\$ 5,317.40$ saving by implementing Option 2. It is important to consider this fact when comparing the two options, as payback period and ROI favour Option 1 due to the lower initial costs.

\section{Recommendations}

The following recommendation have been made based on the results of the thermal comfort modelling, along with the financial analysis based on these results. This will assist homeowner make a decision between Option 1 and 2 .

Table 15 displays the key information for Option 1- Case 2: R3 Ceiling Insulation.

Table 15: Option 1 feasibility analysis results

\begin{tabular}{cc}
\hline \multicolumn{2}{c}{ Option 1- Case 2 R3 Ceiling Insulation } \\
\hline Heating and Cooling Energy Saving \\
Cost of Retrofit & $53 \%$ \\
Savings from Reference Per Year & $\$ 1,344.60$ \\
Payback Period (Months) & $\$ 1,722.95$ \\
20 Year Return on Investment & 10 \\
Return over 20 Years, minus initial cost & $2463 \%$ \\
\hline
\end{tabular}

Option 1 will be recommended for homeowners that want to restrict their initial financial investment amount into retrofitting and would prefer a quick payback period. These include homeowners on a tight budget or will not be living in the home long term. Table 15 
demonstrates the strong effectiveness and viability of this retrofitting technique, essentially halving energy usage while providing a continuing financial savings. Option 1 retrofitting technique should be implemented as a minimal into all dwelling that do not have insulation or insulation that has deteriorated over time.

Table 16 summarises the key information for Option 2 - Case 6: R3 Ceiling + External Wall Insulation. Although Option 2 has an initial cost that is 6 times higher than Option 1, over an extended 20-year period there will be an extra $\$ 5,317.40$ of saving compared to Option 1.

Table 16: Option 2 feasibility analysis results

\begin{tabular}{cc}
\hline \multicolumn{2}{c}{ Option 2 - R3 Ceiling + External Wall Insulation } \\
\hline Heating and Cooling Energy Saving \\
Cost of Retrofit & $71 \%$ \\
Savings from Reference Per Year & $\$ 7,773.60$ \\
Payback Period (Months) & $\$ 2,310.27$ \\
20 Year Return on Investment & 41 \\
Return over 20 Years, minus initial cost & $494 \%$ \\
\hline
\end{tabular}

Option 2 will be recommended for homeowners that are prepared to pay the higher initial cost for the long-term benefits. These include homeowners that have a higher budget, longterm owners such as investors and occupants who wish to enjoy the further improvement to the thermal comfort of the dwelling. Option 2 retrofitting fitting technique is the preferred option due to the further reduction in energy usage, leading to reduced $\mathrm{CO}_{2}$ emissions benefiting the environment. ${ }^{7}$ In general, it is recommended that homeowners use the flowchart illustrated in Figure 11 for their decision making process.

\section{Conclusions}

This study has focused on developing recommendations on the most effective and feasible retrofitting techniques for existing buildings in Sydney metropolitan area by performing financial analysis of initial investment vs return based on the quantitative results of the energy modelling. Thermal comfort modelling software FirstRate5 has been used to simulate the annual heating and cooling energy consumption of nine benchmark buildings through a range of retrofitting techniques. Dwellings of varying construction materials 
including weatherboard, cavity brick and brick veneer have been simulated to improve accuracy. Each case study building has been subjected to seven retrofitting cases to produce a consistent set of results.

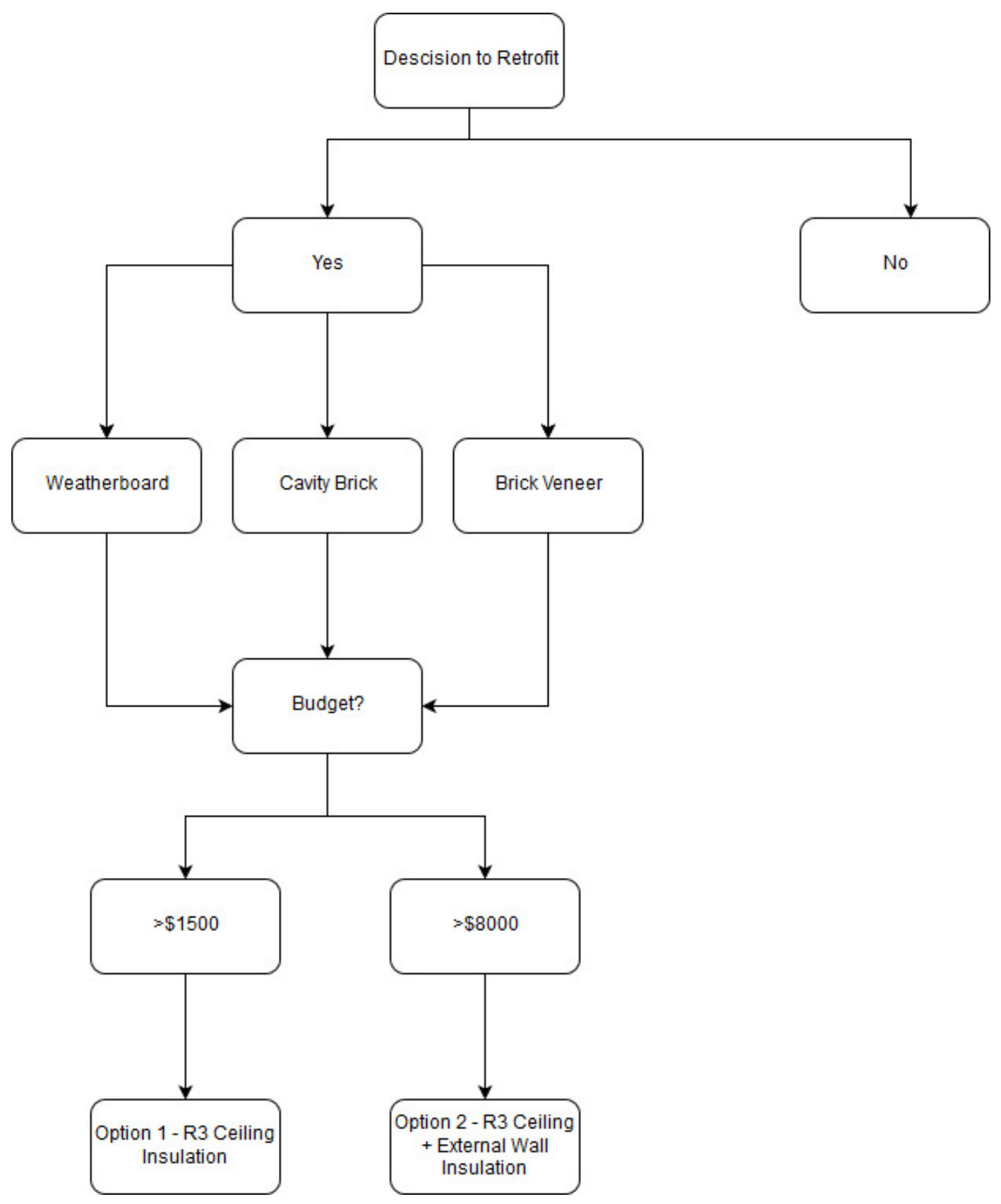

Figure 11: Thermal retrofitting decision making flowchart 
Based on the results of this study, it has become apparent that there is a significant heating and cooling energy reduction by implementing two cases of the examined retrofitting cases to existing residential dwellings in Sydney metropolitan area. Those two cases are Option 1 - Case 2: R3 ceiling insulation and Option 2 - Case 6: R3 ceiling plus external wall insulation. For many homeowners, the decision for retrofitting their dwelling will be made on whether it will be economical or not. Therefore, this study has also demonstrated that Option 1 and Option 2 are worthwhile investments that will provide a financial return. Both options provide a payback period of less than three years, with Option 1 being paid back period within the first year.

Option 1 is recommended for homeowners who want to restrict their initial financial investment amount, preferring a quick payback period. The results demonstrate the strong effectiveness and viability of this retrofitting technique, essentially halving energy usage while providing a continuing financial savings. It is also strongly recommended that Option 1 retrofitting technique be implemented as a minimal into all dwelling that do not have insulation or insulation that has deteriorated over time. Although Option 2 has an initial cost significantly higher than Option 1 , over an extended 20-year period, there will be a substantial extra saving compared to Option 1. Therefore, Option 2 will be recommended to homeowners who are prepared to pay the higher initial cost for the long-term benefits and occupants who wish to enjoy the further improvement to the thermal comfort of the dwelling. Option 2 retrofitting fitting technique is the preferred option due to the further reduction in energy usage and reduced $\mathrm{CO}_{2}$ emissions, leading to environmental benefits. Occupants are strongly encouraged to utilise the decision making flowchart developed in this study for their decision making process. 


\section{References}

1. Poel, B., Cruchten, G \& Balaras, C.A. 2007, 'Energy Performance Assessment of Existing Dwellings', Energy and Buildings, vol. 39, no. 4, pp. 393-403.

2. Power, A. 2008, 'Does Demolition or Refurbishment of Old and Inefficient Homes Help to Increase Our Environmental, Social and Economic Viability', Energy Policy, vol. 36, no. 12, pp. 4487-4501.

3. Thomsen, A. and Flier, L. 2008, 'Replacement or Reuse, the Choice between Demolition and Life Cycle Extension from a Sustainable Viewpoint Shrinking Cities', ENHR International Research Conference Shrinking Cities, Sprawling Suburbs, Changing Country sides, Dublin, Ireland, pp1-13.

4. Gaterell, M.R. \& McEvoy, M.E. 2005, 'The Impact of Climate Change Uncertainties on the Performance of Energy Efficiency Measures Applied to Dwellings', Energy and Buildings, vol. 37, no. 9, pp. 982-995.

5. Brand, S. 1994, How Buildings Learn: What Happens after They Are Built, Viking, New York.

6. Department of Climate Change and Energy Efficiency 2008, Energy Use in the Australian Residential Sector, Commonwealth of Australia, Canberra.

7. Geoscience Australia 2017, Australian Energy Flows, Australian Atlas of Energy Resources, Mines and Processing Centre, Canberra, viewed 5 June 2017, < http://www.australianminesatlas.gov.au/mapping/files/australian_energy_flows_200 6-07.pdf $>$.

8. Department of the Environment, Water, Heritage and the Arts 2008, Energy Use in Australian Residential Sector, DEWHA, Canberra.

9. Lyons, P., and Reardon, C. 2013, Australia's Guide to Environmentally Sustainable Homes. http://www.yourhome.gov.au

10. Lau, W. 2012, 'Model Behaviour: Architects Should Prepare to Take a Leading Role in Energy Modeling, Eco-Structure, American Institute of Architects, http://www.iea.org/publications/freepublications/publication/name,16001,en.html.

11. Zinzi, M. \& Fasano, G. 2009, 'Properties and performance of advanced reflective paints to reduce the cooling loads in buildings and mitigate the heat island effect in urban areas', International Journal of Sustainable Energy, vol. 28, no. 1-3, pp. 123 139.

12. Synnefa, A., Saliari, M. \& Santamouris, M. 2012, ' Experimental, numerical assessment of the impact of increased roof reflectance on a school building in Athens', Energy and Buildings, vol. 55, pp. 7-15.

13. Karabay, H \& Arıc1, M. R. 2012, ' Multiple pane window applications in various climatic regions of Turkey', Energy and Buildings, vol. 25, pp. 67-71.

14. Pisello, A.L. 2017, ' State of the art on the development of cool coatings for 
buildings and cities', Solar Energy, vol. 144, pp. 660-680

15. Mansoury, B. \& Tabatabaiefar, H.R. 2016, 'Application of Sustainable Design Principles to Increase Energy Efficiency of Existing Buildings', Building Research Journal, vol. 6, no. 3, pp. 167-178.

16. Hernández-Péreza, I, Xamánb, J. Macías-Meloa, E.V. Aguilar-CastroaI, E.V. 2018, 'Experimental thermal evaluation of building roofs with conventional and reflective coatings', Energy and Buildings, vol.158, pp. 569-579.

17. Konstantinou, T \& Knaack, U. 2013, 'An Approach to Integrate Energy Efficiency Upgrade into Refurbishment Design Process, Applied in Two Case-Study Building in Northern European Climate', Energy and Buildings, vol.59, pp. 301-309.

18. Australian Building Codes Board 2016, Energy Efficiency Provisions, 4th edn, ABCB, Canberra.

19. Bergman, T.L, Lavine, A.S, Incropera, F.P. and DeWitt, D.P. 2011, Fundamentals of Heat and Mass Transfer, $7^{\text {th }}$ edn, John Wiley and Sons, New Jersey.

20. National Construction Code 2016, NCC Volume 2: Energy Efficiency Provisions, Australian Building Codes Board, Canberra.

21. Ponechal, R. 2015, 'Increasing Thermal Mass in Low Carbon Dwelling', Procedia Engineering, vol. 111, pp 645-651.

22. Reilly, A. and Kinnane, O. 2017, 'The Impact of Thermal Mass on Building Energy Consumption', Applied Energy, vol. 52, pp. 108-121.

23. Sustainable Energy Authority Victoria 2006, Energy Smart Housing Manual, viewed June 2017 〈http://www.aprbuildingservices.com.au/Files_ESHM/ESHousingManualCh07.pdfs >

24. Iyer-Raniga, U. \& Wong, J.P.C. 2012, 'Evaluation of Whole Cycle Assessment for Heritage Buildings in Australia', Building and Environment, vol. 47, pp.138-149.

25. Sustainability Victoria 2016, 'Cavity Wall Insulation Retrofit Trial', viewed May 2017, http://www.sustainability.vic.gov.au/-/media/resources/documents/servicesand-advice/households/energyefficiency/retrofit-trials/cavity-wall-insulationretrofit-trial-sep-2016.pdf?la=en

26. ANSI/ASHRAE Standard 55-2013, Thermal Environmental Conditions for Human Occupancy, American National Standards Institute, Atlanta.

27. AGL New South Wales Electricity Residential Single Rate Fact Sheet, viewed May 2017 https://www.agl.com.au/ /media/AGL/Residential/Documents/Plans\%20and\%20Pri cing/2015/ECNSW\%20Update\%207\%20Apr/Country\%20Energy/PriceFactSheet AGD20833MR.PDF 